\title{
Why Only Efficiency, and Not Efficacy, Matters in Psychotherapy Practice
}

\author{
Henrik Berg ${ }^{1,2 *}$ \\ ${ }^{1}$ Centre for the Study of the Sciences and the Humanities, Faculty of Humanities, University of Bergen, Bergen, Norway, \\ ${ }^{2}$ Centre for Sustainable Healthcare Education, Faculty of Medicine, University of Oslo, Oslo, Norway
}

Evidence-based practice in psychology consists of two quality parameters. One of these quality parameters is efficacy and the other is efficiency. In this article, it is argued that the only relevant parameter for determining quality in clinical care is efficiency. Moreover, emphasising efficacy in psychotherapy practice is symptomatic of a scientocentric ideal in evidence-based practice in psychology. The proper understanding and use of scientific findings entail leaving this scientocentric ideal. In addition, it is crucial that efficiency is related to the ethical aims that constitutes psychotherapy practice.

\section{OPEN ACCESS}

Edited by: Roberto Cattivelli,

Istituto Auxologico Italiano (IRCCS),

Reviewed by:

Lisa A. Osborne,

The Open University, United Kingdom Neusa Sica Rocha, Federal University of Rio Grande do Sul, Brazil

${ }^{*}$ Correspondence: Henrik Berg

henrik.berg@uib.no

Specialty section: This article was submitted to Psychology for Clinical Settings, a section of the journal Frontiers in Psychology

Received: 07 September 2020 Accepted: 08 April 2021 Published: 07 May 2021

Citation: Berg H (2021) Why Only Efficiency, and Not Efficacy, Matters in Psychotherapy Practice. Front. Psychol. 12:603211. doi: 10.3389/fpsyg.2021.603211
Keywords: effectiveness and efficiency, critique, psychotherapy practice and research, evidence-based practice in psychology, facts and values

\section{INTRODUCTION}

Cochrane's (1999) "Effectiveness and efficiency" set new standards for medical practice. He argued that without the guidance of randomised controlled trials, medical doctors delivered suboptimal, and sometimes even harmful, services. Because randomised controlled trials were believed to be bias-free, and consequently did not share the biases that led medical doctors to provide suboptimal treatment, Cochrane (1999) wanted randomised controlled trials to be the building blocks of a modernised health-care system. Randomisation aims at providing (a minimum of) two similar groups that are tested in controlled experimental conditions. Any difference in outcome is attributed to the intervention which is normally given to one of the groups only.

Cochrane used the term "effectiveness" to denote the scientific merits of a given treatment. Cochrane recognises that he uses the term effectiveness to denote what is commonly coined "efficacy" (which he avoids simply because he dislikes the word). More specifically, effectiveness refers to the causal effects of a treatment. A treatment is deemed "effective" if scientific findings indicates that it causes a given change in the health status of its recipients. According to Cochrane, randomised controlled trials are superior in bringing about information of causal factors. Due to their lack of bias, randomised controlled trials let researchers draw unequivocal inferences (of whether a treatment is effective or not). Thus, there is an implicit methodological hierarchy in Cochrane's ideal for clinical science, but Cochrane's ideal for science and practice are not identical.

There is an often-overlooked political ambition of Cochrane's thinking, which was to provide effective health-care treatment available for everyone. This political aim led him to coin a second term. Efficiency includes factors such as the economic cost of various treatment options and the optimal use of staff and equipment. Efficiency is the translation of scientific research in clinical 
setting, taking the most important external (i.e., extra-scientific) factors into consideration. By distinguishing effectiveness and efficiency, Cochrane underscored that clinical science differs from clinical practice. Whereas the models of science constructively reduce complexity, the reduction of complexity in clinical practice is associated with the risk of suboptimal clinical care.

Another important distinction in Cochrane's thinking is that between cure and care. Cochrane used the term cure to denote the combination of effectiveness and efficiency. One reason for combining effectiveness and efficiency in a concept is to highlight that effective treatments have variable efficiency in different contexts. Thus, one could either identify more effective cures or change the clinical setting to increase efficiency. $\mathrm{He}$ also introduced the term care, which are the affectionate aspects of patient treatment (in his own words, "tender" and "loving") (Cochrane, 1999). While recognising that care is important in actual health-care practice, Cochrane's recipe for better health-care services was improving cure, particularly emphasising effectiveness. The vision that Cochrane presented in "Effectiveness and efficiency" has led to a major restructuring of health-care systems world-wide (Timmermans and Berg, 2003; Claridge and Fabian, 2005; Shah and Chung, 2009; Sur and Dahm, 2011).

\section{EVIDENCE-BASED MEDICINE}

The legacy of Cochrane prevails in evidence-based medicine and other evidence-based health-care practices. The effectivenessefficiency distinction exists (albeit in new forms) in most evidence-based medicine models (Sackett, 1997). However, there are some notable differences between Cochrane's thinking and evidence-based medicine. Whereas Cochrane (1999) insisted that randomised controlled trials are necessary to provide best treatment, contemporary evidence-based medicine's conceptualisation of best evidence is more flexible (Guyatt and Rennie, 2002). These models have an evidence-based hierarchy ranging randomised controlled trials (and compilations of randomised controlled trials in systematic reviews and metaanalyses) as the most stringent types of evidence. However, through the GRADE-system, research studies are evaluated and ranked from "high" to "very low." Accordingly, randomised controlled trials with biases can have a ranking of "low" or even "very low" and observational studies can have a ranking of "moderate" or "high." Although the GRADE-system determine treatment efficacy, it is also relevant for the understanding of effectiveness. Once it is recognised that different kinds of methodologies, and not only randomised controlled trials, can provide useful insight, it opens up for the active interpretation of evidence. The latter versions of evidence-based medicine emphasise the clinical importance of a clinical expert and de-emphasise the direct clinical importance of randomised controlled trials (Haynes et al., 2002).

In contrast to Cochrane's model, the more recent evidencebased medicine models are tripartite and consists of best external evidence, clinical expertise and patient values (Guyatt, 1991;
The Evidence-Based Medicine Working Group, 1992; Sackett et al., 1996; Sackett, 1997; Haynes et al., 2002). This is a fairly important development, because it complicates the notion of efficiency. In accordance with Cochrane, the clinical expert is deemed necessary to convert the best external evidence into best clinical practice. Whereas science consists of propositions typically describing effects, clinical experts translate the scientific findings in a given clinical context. Second, patient values must be included in treatment. This sharpens the distinction between efficacy and efficiency, because patient preferences might diverge from the evidence base. According to this ideal, a treatment can hardly be called efficient, if its effects are not welcomed by the patient. Thus, in the tripartite evidence-based medicine models, efficiency entails individualised treatments.

\section{EVIDENCE-BASED PRACTICE IN PSYCHOLOGY}

Evidence-based medicine was the template for the American Psychological Association's policy statement for evidence-based practice in psychology (Levant, 2005). The authors of the policy-statement declares that [e]vidence-based practice in psychology is [...] consistent with the past 20 years of work in evidence-based medicine (Levant, 2005, p. 271). Evidencebased practice in psychology is defined as: "the integration of the best available research with clinical expertise in the context of patient characteristics, culture, and preferences" (American Psychological Association, 2006, p. 273). However, evidencebased practice in psychology is an unsuccessful attempt to create a tripartite model. It actually exists of only one part, which is best available research. Thus, clinical expertise and patient characteristics, culture and preferences are in fact scientific subcategories (Berg, 2019). In addition, the integration of these (alleged) three parts have not been substantiated. It is the clinical expert that must integrate the different elements in evidencebased practice. Thus, the competence of the clinician must somehow reflect the three (alleged) parts in evidence-based practice in psychology (Berg, 2020). The consequence of these failings is that evidence-based practice in psychology contains a direct link from scientific evidence to clinical practice. In spite of major short-comings, it continues to be the dominating regulating principle for psychotherapy practice (Levant, 2005).

However, there are also problems with regards to the definition of best evidence, in evidence-based practice in psychology. At first sight, the notion of evidence in the policy statement is quite inclusive. It contains a section with the heading "multiple types of research evidence." Under this heading it is argued that " $[\mathrm{m}]$ ultiple research designs contribute to evidence-based practice, and different research designs are better suited to address different types of questions" (Levant, 2005 , p. 274). Some of the research methods mentioned are "clinical observation," "systematic case-studies," and "qualitative methods." These methods typically have a lower standing in evidence-based practice (miscellaneous). In addition, methods such as RCTs and meta-analyses are included (Levant, 2005). 
However, another section of the policy-statement describes "specific interventions" (Levant, 2005). In this section, Cochrane's distinction between effectiveness and efficiency re-emerges (Cochrane, 1999) with the concepts treatment efficacy and clinical utility:

Treatment efficacy is defined as the systematic and scientific evaluation of whether a treatment works. Clinical utility, on the other hand, is defined as the applicability, feasibility, and usefulness of the intervention in the local or specific setting where it is to be offered. Clinical utility also includes determination of the generalisability of an intervention whose efficacy has been established (Levant, 2005, p. 275).

In the quality parameter called treatment efficacy there is a distinction between three different types of evidence forming an evidence hierarchy. The least reliable kind of evidence is clinical opinion, observation and consensus followed by systematised clinical observation. Randomised controlled experiments [sic] at the top of the hierarchy. The policy statement argues that randomised controlled experiments "represent a more stringent way to evaluate treatment efficacy because they are the most effective way to rule out threats to internal validity in a single experiment" (Levant, 2005, p. 275). This reasoning resonates Cochrane's stance on randomised controlled trials.

If randomised controlled trials are preferred for evaluating treatment efficacy for specific interventions, the notion of specific intervention in psychotherapy needs clarification. A specific intervention is not the same as a specific technique (e.g., exposure-therapy or behavioural experiment) (Bennet-Levy et al., 2004; Chrétien et al., 2017). If a psychotherapist is intervening to strengthen the affective bond (as a part of the therapeutic alliance) (Horvath and Bedi, 2002; Horvath et al., 2011), the intervention is specific, but it does not necessarily involve a specific technique. If every intervention with a given aim is defined a specific intervention, most therapist interventions are indeed specific. It follows that the evidence-hierarchy applies to every therapeutic action, in the widest sense of the word. Thus, randomised controlled trials are preferred to indicate efficacy. Consequently, randomised controlled trials are as dominant in evidence-based practice in psychology as in evidence-based medicine, only with the disadvantage of being dominant in a somewhat opaque manner.

Cochrane's distinction between care and cure has been confused by the authors of the policy-statement for evidencebased practice in psychology. The very distinction is obsolete in psychotherapy, because care (e.g., empathy, congruence, affective bond, etc.) is the better part of cure (i.e., what makes psychotherapy work) (Norcross, 2011; Wampold, 2015; Wampold and Imel, 2015). A grim example is the attempt to create a list of "empirically validated/supported psychotherapies" based on a narrow understanding of psychotherapy (Chambless et al., 1993). The same misunderstanding seems to have informed the policy-statement for evidence-based practice in psychology. It is very unclear what the actual role of other research designs is to be in actual practice.

The other quality parameter is clinical utility. In the policystatement it is argued that:
At a minimum this includes attention to generality of effects across varying and diverse patients, therapists, settings, and the interaction of these factors; the robustness of treatments across various modes of delivery; the feasibility with which treatments can be delivered to patients in real-world settings; and the costs associated with treatments (Levant, 2005, p. 275).

Clinical utility denotes the ability to combine different sources of knowledge to find the optimal treatment in reallife settings. In addition, clinical utility includes economic factors. Leaving economic factors aside, it should be clear that that the definition of an optimal real-world treatment is by no means straightforward. There is a large number of fact and value entanglements in psychotherapy practice making the notion of utility equivocal. Clinical practice concerns itself with the unique individual patient. The most relevant question when facing an individual is whether one has the knowledge, skill and resources to help that very individual. If the clinician has knowledge about effects that do not pertain to that very individual, lack the skill to convert knowledge into practice and/or do not have the resources to provide the treatment, knowledge about a given form of treatment is irrelevant. In that sense, knowledge about treatment efficacy qua treatment efficacy is useless for clinical practice. It is useful if and only if it leads to clinical utility. Thus, insofar that evidence-based practice in psychology aims at regulating psychotherapy practice, the only relevant parameter is clinical utility.

The move from empirically supported treatments (Chambless and Hollon, 1998; Chambless et al., 1998; Chambless, 1999) to evidence-based practice in psychology was supposed to be a move toward a more inclusive ideal for best practice (Levant, 2004; Peterson, 2004). Nonetheless, evidence-based practice in psychology have remains of the scientism of empirically supported treatments (Chambless et al., 1993, 1998; Chambless and Hollon, 1998; Chambless, 1999). One of these is that scientific findings per se serves as quality indicator of clinical practice. However, treatment efficacy is only be a quality indicator for research and not for practice.

The proper understanding of efficiency comes with a major caveat. The sound use of scientific research in psychotherapy practice depends on the conceptualisation of psychotherapy. The propositions of psychotherapy research are value-laden and the various psychotherapy schools and interventions merges with ethics (Tjeltveit, 1999, 2004; Woolfolk, 2015; Berg and Slaattelid, 2017). Psychotherapy schools are constituted by differing normative claims. As an example, the normative aim of existential psychotherapy differs from that of cognitivebehavioural therapy. Any consideration of research findings for clinical practice has to take this facet of psychotherapy into consideration. Empirical research cannot determine the nature of the good. The good and the right are the subjects of normative ethics. Thus, there is an inherent and principal limitation in scientific research when informing psychotherapy practice.

When defining "real-world effects" one has to take into consideration that psychotherapy aims at realising a vision of 
a better life (Waring, 2016; Berg, 2020). This entails that moral and ethics are quintessential to psychotherapy. High quality science can be very helpful in achieving many of those aims, but it presupposes a sensible conceptualisation of the relationship between science and practice. Thus, all in all, ethics must come first and science come second.

\section{CONCLUSION}

Because the policy-statement for evidence-based practice in psychology aims at regulating practice through scientific and extra-scientific parameters, it should encompass the difference between science and practice. In the current version of the policy-statement there is a failed attempt to achieve this. This does not only lead to a series of misunderstandings as to what makes psychotherapy "work," but also with misunderstandings of what psychotherapy is. Ultimately, the distance from science (as it is defined in evidence-based practice in psychology) to clinical practice is considerable, because the former deal with empirical regularities at a group level and the latter deal with the realisation of a better life at the level of the individual. Without sorting

\section{REFERENCES}

American Psychological Association. (2006). Policy statement on evidence-based practice in psychology. Am. Psychol. 61, 271-285. doi: 10.1037/0003-066X.61.4. 271

Bennet-Levy, J., Westbrook, D., Fennel, M., Cooper, M., Rouf, K., and Hackmann, A. (2004). "Behavioural experiments: historical and conceptual underpinnings," in Oxford guide to behavioural experiments in cognitive therapy, eds J. BennetLevy, G. Butler, M. Fennel, A. Hackman, M. Mueller, and D. Westbrook (Oxford: Oxford University Press).

Berg, H. (2019). Evidence-based practice in psychology fails to be tripartite: a conceptual critique of the scientocentrism in evidence-based practice in psychology. Front. Psychol. 10:2253. doi: 10.3389/fpsyg.2019.02253

Berg, H. (2020). Virtue ethics and integration in evidence-based practice in psychology. Front. Psychol. 11:258. doi: 10.3389/fpsyg.2020.00258

Berg, H., and Slaattelid, R. (2017). Facts and values in psychotherapy: a critique of the empirical reduction of psychotherapy within evidence-based practice. J. Eval. Clin. Pract. 23, 1075-1080. doi: 10.1111/jep.12739

Chambless, D. L. (1999). Empirically validated treatments - What now? Appl. Prev. Psychol. 8, 281-284. doi: 10.1016/S0962-1849(05)80043-5

Chambless, D. L., Babich, K., Crits-Christoph, P., Frank, E., Gilson, M., and Montgomery, R. et al. (1993). Task Force On Promotion And Dissemination Of Psychological Procedures. Washington, D.C.: American Psychological Association.

Chambless, D. L., Baker, M. J., Baucom, D. H., Beutler, L. E., Calhoun, K. S., CritsChristoph, P., et al. (1998). Update on empirically validated therapies II. Clin. Psychol. 51, 3-16.

Chambless, D. L., and Hollon, S. D. (1998). Defining empirically supported therapies. J. Consult.Clin. Psychol. 66, 7-18. doi: 10.1037/0022-006X.66.1.7

Chrétien, M., Giroux, I., Goulet, A., Jacques, C., and Bouchard, S. (2017). Cognitive restructuring of gambling-related thoughts: a systematic review. Addict. Behav. 75, 108-121. doi: 10.1016/j.addbeh.2017.07.001

Claridge, J. A., and Fabian, T. C. (2005). History and development of evidence-based medicine. World J.Surg. 29, 547-553. doi: 10.1007/s00268-0057910-1

Cochrane, A. L. (1999). Effectiveness And Efficiency: Random Reflections On Health Services. London: Royal Society of Medicine Press. out these misconstructions, there is little hope that evidencebased practice in psychology could serve as a satisfactory regulatory principle.

\section{DATA AVAILABILITY STATEMENT}

The original contributions presented in the study are included in the article/supplementary material, further inquiries can be directed to the corresponding author/s.

\section{AUTHOR CONTRIBUTIONS}

The author confirms being the sole contributor of this work and has approved it for publication.

\section{FUNDING}

This work was supported by the Centre for the Study of the Sciences and the Humanities, Faculty of Humanities, University of Bergen and Centre for Sustainable Healthcare Education, Faculty of Medicine, University of Oslo.

Guyatt, G. (1991). Evidence-based medicine. ACP J. Club 114:16. doi: 10.7326/ ACPJC-1991-114-2-A16

Guyatt, G. H., and Rennie, D. (2002). Users' Guide to the Medical Literature: a Manual for Evidence-Based Clinical Practice. Chicago: AMA Press.

Haynes, B., Devereaux, P. J., and Guyatt, G. (2002). Clinical expertise in the era of evidence-based medicine and patient choice. BMJ 136, 383-386. doi: 10.1111/j. 1423-0410.2002.tb05339.x

Horvath, A. O., and Bedi, R. P. (2002). "The alliance," in Psychotherapy relationships that work: therapist contributions and responsiveness to patients, ed. J. C. Norcross (New York: Oxford University Press).

Horvath, A. O., Del, Re, A. C., Flückiger, C., and Symonds, D. (2011). Alliance in individual psychotherapy. Psychotherapy 48, 9-16. doi: 10.1037/a0022186

Levant, R. F. (2004). The empirically validated treatments movement: a practitioner/educator perspective. Clin. Psychol. 11, 219-224. doi: 10.1093/ clipsy.bph075

Levant, R. F. (2005). Report of the 2005 Presidential Task Force on evidence-based practice. URL: https://www.apa.org/practice/resources/evidence/evidencebased-report.pdf

Norcross, J. C. (2011). Psychotherapy Relationships That Work: Evidence-Based Responsiveness. New York, NY: Oxford University Press.

Peterson, D. R. (2004). Science, scientism, and professional responsibility. Clin. Psychol. 11, 196-210. doi: 10.1093/clipsy.bph072

Sackett, D. L. (1997). Evidence-based medicine. Semin. Perinatol. 21, 3-5. doi: 10.1016/S0146-0005(97)80013-4

Sackett, D. L., Rosenberg, W. M. C., Gray, J. A. M., Haynes, R. B., and Richardson, W. S. (1996). Evidence based medicine: What it is and what it isn't. Br. Med. J. 312, 71-72. doi: 10.1136/bmj.312.7023.71

Shah, H. M., and Chung, K. C. (2009). Archie Cochrane and his vision for evidence-based medicine. Plast. Reconstr. Surg. 124, 982-988. doi: 10.1097/PRS. 0b013e3181b03928

Sur, R. L., and Dahm, P. (2011). History of evidence-based medicine. Indian J. Urol. 27, 487-489. doi: 10.4103/0970-1591.91438

Timmermans, S., and Berg, M. (2003). The Gold Standard: The Challenge Of Evidence-Based Medicine And Standardization In Health Care. Philadelphia: Temple University Press.

Tjeltveit, A. C. (1999). Ethics And Values In Psychotherapy. London: Cambridge University Press. 
Tjeltveit, A. C. (2004). The good, the bad, the obligatory, and the virtuous: the ethical contexts of psychotherapy. J. Psychother. Integr. 14, 149-167. doi: 10.1037/1053-0479.14.2.149

The Evidence-Based Medicine Working Group. (1992). Evidencebased medicine: a new approach to teaching the practice of medicine. JAMA 268, 2420-2425. doi: 10.1001/jama.1992.0349017009 2032

Wampold, B. (2015). How important are the common factors in psychotherapy? An update. World Psychiatry 14, 270-277. doi: 10.1002/wps. 20238

Wampold, B., and Imel, Z. E. (2015). The Great Psychotherapy Debate: The Evidence For What Makes Psychotherapy Work. United Kingdom: Routledge.

Waring, D. R. (2016). The Healing Virtues. Oxford: Oxford University Press.
Woolfolk, R. L. (2015). The Value Of Psychotherapy: The Talking Cure In An Age Of Clinical Science. New York, NY: The Guilford Press.

Conflict of Interest: The author declares that the research was conducted in the absence of any commercial or financial relationships that could be construed as a potential conflict of interest.

Copyright (C) 2021 Berg. This is an open-access article distributed under the terms of the Creative Commons Attribution License (CC BY). The use, distribution or reproduction in other forums is permitted, provided the original author(s) and the copyright owner(s) are credited and that the original publication in this journal is cited, in accordance with accepted academic practice. No use, distribution or reproduction is permitted which does not comply with these terms. 